\title{
Extrahepatic Bile Duct Fibroma
}

National Cancer Institute

\section{Source}

National Cancer Institute. Extrahepatic Bile Duct Fibroma. NCI Thesaurus. Code C5853.

A benign neoplasm arising from the extra hepatic bile duct. It is characterized by the presence of spindle-shaped fibroblasts. 